Biochimica et Biophysica Acta, 464 (1977) 295-312

(C) Elsevier/North-Holland Biomedical Press

BBA 77579

\title{
ROLE OF PROTON DISSOCIATION IN THE TRANSPORT OF ACIDIC AMINO ACIDS BY THE EHRLICH ASCITES TUMOR CELL *
}

\author{
JAVIER GARCIA-SANCHO **, ANA SANCHEZ ** and HALVOR N. CHRISTENSEN *** \\ Department of Biological Chemistry, The University of Michigan, Ann Arbor, Mich. 48109 \\ (U.S.A.)
}

(Received May 25th, 1976)

(Revised manuscript received September 20th, 1976)

\section{Summary}

The $\mathrm{pH}$ profile for the uptake of L-glutamic acid by the Ehrlich ascites tumor cell arises largely as a sum of the decline with falling $\mathrm{pH}$ of a slow, $\mathrm{Na}^{+}$-dependent uptake by System $\mathrm{A}$, and an increasing uptake by $\mathrm{Na}^{+}$-independent System $\mathrm{L}$. The latter maximizes at about $\mathrm{pH} 4.5$, following approximately the titration curve of the distal carboxyl group. This shift in route of uptake was verified by (a) a declining $\mathrm{Na}^{+}$-dependent component, (b) an almost corresponding decline in the 2-(methylamino)-isobutyric acid-inhibitable component, (c) a rising component inhibited by 2 -aminonorbornane-2-carboxylic acid. Other amino acids recognized as principally reactive with Systems A or L yielded corresponding inhibitory effects with some conspicuous exceptions: 2-Aminoisobutyric acid and even glycine become better substrates of System $\mathrm{L}$ as the $\mathrm{pH}$ is lowered; hence their inhibitory action on glutamic acid uptake is not lost. The above results were characterized by generally consistent relations among the half-saturation concentrations of the interacting amino acids with respect to: their own uptake, their inhibition of the uptake, one by another, and their trans stimulation of exodus, one by another.

A small $\mathrm{Na}^{+}$-dependent component of uptake retained by L-glutamic acid but not by $\mathrm{D}$-glutamic acid at $\mathrm{pH} 4.5$ is inhibitable by methionine but by neither 2 . (methylamino)-isobutyric acid nor the norbornane amino acid. We provisionally identified this component with System ASC, which transports L-glutamine throughout the $\mathrm{pH}$ range studied. No transport activity specific to the anionic amino acids was detected, and the unequivocally anionic cysteic acid showed neither significant mediated uptake nor inhibition of the uptake of glutamic acid or of the norbornane amino acid.

\footnotetext{
* Preliminary reports of parts of this work have appeared $[1-3]$.

** Present address: Departamento de Fisiologia y Bioquimica, Facultad de Medicina, Valladolid, Spain *** To whom requests for reprints should be addressed.
} 
The dicarboxylic amino acids take the sequence, aspartic acid < glutamic acid $<\alpha$-aminoadipic acid $<S$-carboxymethylcysteine, in their rate of mediated, $\mathrm{Na}^{+}$-independent uptake at low $\mathrm{pH}$. Diiodotyrosine and two dissimilar isomers of nitrotyrosine also show acceleration of uptake as the phenolate group on the sidechain is protonated, a result indicating that the acidic group need not be a carboxyl group and need not take a specific position in space to be accepted at the receptor site $\mathrm{L}$. The presence of the carboxyl group does not upset the normal stereospecificity of System L until it falls on the $\beta$-carbon in aspartic acid; even then it is the presence of the carbonyl group and not of the intact carboxyl group nor of its hydroxyl group that cancels out the stereospecificity, as was shown by the absence of normal stereospecificity for aspartic acid and asparagine and its presence in glutamic acid, homoserine and glutamine. In agreement, the uptake of aspartic acid is peculiarly sensitive to the presence of an $\alpha$-methyl group or of other structures that modify the orientation of the sidechain.

\section{Introduction}

In contrast to the situation with the neutral and the cationic amino acids, our knowledge of the routes of uptake of the acidic amino acids by the Ehrlich cell is in an unsatisfactory state. We noted earlier that their uptake is sluggish [4]. Heinz et al. [5] showed that L-glutamate is taken up into the Ehrlich cell by a mediated process, although the system implicated was believed to be a new one showing some unusual characteristics (Heinz et al. [6]): (1) Transport interactions with other acidic amino acids were immeasurably small; (2) uptake was strongly stimulated by lowering the $\mathrm{pH}$ of the suspending medium, in contrast to what happens with most of the neutral and cationic amino acids; (3) neutral amino acids were inhibitory, but these effects were half-saturated at concentrations not corresponding to $K_{\mathrm{m}}$ values for their uptake.

In the present paper we analyze the transport agencies participating in the uptake of acidic amino acids by the Ehrlich cell. We find that uptake takes place largely by the two main systems for neutral amino acids, without any indications for the operation here of a system specific to anionic amino acids. (For a review on the transport systems in the Ehrlich cell see ref. 7.) Transport of glutamic acid by the two neutral systems shows approximately opposite responses to changes in the $\mathrm{pH}$. The meaning of these effects is explored, and the structural requirements for the transport of these amino acids by one of these systems (L) is studied in detail.

\section{Materials and Methods}

The amino acids were either obtained from standard commercial sources, or synthesized in this laboratory. We are indebted to Dr. Alvie L. Davis of Abilene Christian College for the sample of 5 '-hydroxy-2'-nitro-DL-phenylalanine, and to Dr. Joseph Burckhalter, by way of the Parke Davis Co., for the sample of $2^{\prime}$ hydroxy-5'-nitro-DL-phenylalanine [8] .

2-(Methylamino)-isobutyric acid was prepared by the Strecker reaction as 
previously described [9] but at $60^{\circ} \mathrm{C}$ in a tightly stoppered flask, and using methylamine hydrochloride that had been freed of $\mathrm{NH}_{4} \mathrm{Cl}$. The amine hydrochloride was twice treated with portions of an aqueous solution of methylamine, and each time evaporated to dryness. Contamination of the product with 2-aminoisobutyric acid is avoided in this way. 2-Aminonorbornane-2-carboxylic acid, as the $( \pm) \mathrm{b}$-isomer [10], and L-cysteic acid [11], were prepared in this laboratory, both in ${ }^{14} \mathrm{C}$-labeled and unlabeled forms.

\section{Synthesis of 1-aminocyclohexane-1,2-dicarboxylic acid}

The following compounds were mixed in a test tube in this order: $1.25 \mathrm{~g}$ of $\left(\mathrm{NH}_{4}\right)_{2} \mathrm{CO}_{3}$ in a mixture of $5 \mathrm{ml}$ each of ethanol and water; $0.8 \mathrm{ml}(5 \mathrm{mmol})$ of cyclohexanone-2-carboxylic acid ethyl ester, which was dissolved by warming to $40^{\circ} \mathrm{C}$ in a stoppered tube; $0.37 \mathrm{~g}$ of $\mathrm{KCN}$ in $2 \mathrm{ml}$ of ethanol/water $(1: 1$, $\mathrm{v} / \mathrm{v}$ ). The tube was sealed and held at $50^{\circ} \mathrm{C}$ for $5 \mathrm{~h}$. The solution was taken to about $7 \mathrm{ml}$ in vacuo, chilled, and the crystalline produce washed with water. Titration showed that the ester link survived this treatment. Saponification at $100^{\circ} \mathrm{C}$ showed approximately the theoretical equivalent weight of $240 \mathrm{~g}$ for the crystals. Yield of the hydantoin, $0.8 \mathrm{~g} ; \mathrm{p} K^{\prime}$ on $\mathrm{NaOH}$ titration $\left(25^{\circ} \mathrm{C} ; \Gamma / 2=\right.$ $0.15)=9.3$. The hydantoin was dissolved in $8 \mathrm{ml}$ glacial acetic acid in an ignition tube, $8 \mathrm{ml} 6 \mathrm{M} \mathrm{HCl}$ added, and the tube sealed. Hydrolysis was carried out in an autoclave at $124^{\circ} \mathrm{C}$ for $24 \mathrm{~h}$. The hydrolysate was taken to dryness and the residue extracted with an $1: 1(\mathrm{v} / \mathrm{v})$ mixture of ethanol and ether. The extracted material in water solution was titrated to $\mathrm{pH} 2.0$ with amberlite IR4B in the free amine form. Fractional crystallization on evaporation gave two isomeric amino acids, a low solubility one in $24 \%$ overall yield, and a high solubility one in $8 \%$ yield. A mixture of $62 \%$ of the more soluble isomer with $38 \%$ of the less soluble isomer showed an apparent $\mathrm{p} K_{2}^{\prime}$ of 3.8 , corresponding mainly to the titration of the distal carboxyl group. For aspartic acid $\mathrm{p} K_{2}^{\prime}=3.8$. In a parallel small scale synthesis using $\mathrm{K}^{14} \mathrm{CN}$, the isomers were separated on a resin column, monitoring the effluent by radioactive counting. The more soluble isomer emerged at $88 \mathrm{~min}$ on a $60 \times 0.9 \mathrm{~cm}$ polystyrene sulfonate resin column, eluting with $\mathrm{pH} 3.25$ buffer, $80 \mathrm{ml} / \mathrm{h}$. After $90 \mathrm{~min}$ the buffer was changed to $\mathrm{pH}$ 4.25. The less soluble isomer emerged at $131 \mathrm{~min}, 7 \mathrm{~min}$ after the appearance of the second buffer.

The methods of collecting and handling the Ehrlich cell have been described in prior papers [12-14]. The uptake experiments were started by adding 0.3 $\mathrm{ml}$ of a $50 \%$ cell suspension in $0.15 \mathrm{M}$ choline chloride to $3 \mathrm{ml}$ of the incubation medium containing the test amino acid, plus tracer amounts of the appropriate radioactive amino acid when desired. After a measured interval at $37^{\circ} \mathrm{C}$, uptake was terminated by pouring $10 \mathrm{ml}$ of ice-cold isotonic choline chloride into the incubation flasks, followed instantly by a 2 -min centrifugation at 2500 $\mathrm{rev} . / \mathrm{min}$. The supernatant solutions were then decanted, the residual fluid removed from the cell pellet by touching with pointed strips of filter paper, and the cell pellet weighed and extracted with $1 \mathrm{ml}$ of $3 \%$ sulfosalicylic acid. For the exodus experiments, cells were first loaded with the test substrate for 5 min at $37^{\circ} \mathrm{C}$ in modified Krebs-Ringer phosphate solution, $\mathrm{pH} 7.4$, and exodus observed from cold-washed cells for $1 \mathrm{~min}$ at $37^{\circ} \mathrm{C}$, the volume of suspending solution always being at least 200 times the volume of cellular water. Uptake 
was terminated by ice-cold-dilution and centrifugation, the cell pellets and supernatant solutions being processed as described above.

Aliquots of the cell extracts and supernatant solutions were assayed for radioactivity by scintillation counting [14], or their amino acid content determined using the amino acid analyzer. In the case of the hydroxynitro derivatives of phenylalanine, the amino acid was determined from its light absorption at 400 $\mathrm{nm}$ in alkalinized aliquots of the cell extracts or the suspending solutions. Total water in the cell pellet was determined from the loss of weight during $12 \mathrm{~h}$ at $100^{\circ} \mathrm{C}$; the extracellular water was estimated as sucrose space, $0.2 \%$ sucrose being added to the ice-cold diluent and its concentration in the final extracts and supernatant solutions determined by a spectrophotometric procedure [15].

The apparent intracellular $\mathrm{pH}$ was calculated from the distribution between the cells and the extracellular fluid of $\left[{ }^{14} \mathrm{C}\right]$ salicylic acid added to the ice-cold diluent, under the usual principle, in a procedure developed for the purpose.

Some experiments at $\mathrm{pH} 7.4$ were carried out in typical Krebs-Ringer bicarbonate solution. In other instances, a modified Krebs-Ringer phosphate solution containing only $0.5 \mathrm{mM}$ calcium was used instead, or a solution of similar ionic composition, except that $\epsilon$-aminocaproic or morpholinoethanesulfonic acid was used as buffer instead of phosphate. In all cases the osmolarity of the medium was kept at $310 \pm 5 \operatorname{mos} M / 1$, choline chloride being used except where otherwise indicated to compensate for the removal of $\mathrm{Na}^{+}$(in the case of $\mathrm{Na}^{+}$free or low- $\mathrm{Na}^{+}$media) or its concentration varied according to the amount of other extra solutes added (for example amino acids). The changes in $\mathrm{pH}$ of the medium produced negligible changes in the cell water content and distribution under our experimental conditions, a small increase of the water content (both intra- and extracellular in about the same extent) being noticed only when incubation was prolonged up to $10 \mathrm{~min}$ or more. Note that the exposure of the cells to lower $\mathrm{pH}$ was usually only $1-3 \mathrm{~min}$. Intracellular $\mathrm{K}^{+}$levels were also slightly lowered by incubation at low $\mathrm{pH}$, a stoichiometrical relation (about $2: 1$ ) being observed between the loss of internal $\mathrm{K}^{+}$and the uptake of $\mathrm{H}^{+}$from the medium, measured by a titrimetic procedure.

When we studied uptake of radioactively labelled amino acids at low $\mathrm{pH}$ we uncovered previously unobserved contaminants that tended to be fixed by the cells more quickly than the amino acid per se. All the radioactively labelled amino acids were examined for the criterion of radiochemical purity that their uptake be independent of the number of cells per volume of suspension [16] and, if necessary, freed of the contaminant by exposing the preparation to successive lots of Ehrlich cells until they met that standard.

\section{Results}

The $\mathrm{pH}$ profile for the uptake of L-glutamic acid from $\mathrm{Na}^{+}$-containing and $\mathrm{Na}^{+}$-free medium is illustrated in Fig. 1 . The uptake was strongly enhanced on lowering the $\mathrm{pH}$ of the incubation medium, corresponding to the profile previously reported by Heinz et al. [6]. Most of the uptake was $\mathrm{Na}^{+}$dependent at pH 7.4, but it became progressively more $\mathrm{Na}^{+}$insensitive on lowering of the $\mathrm{pH}$ of the medium, the observed stimulation being unaffected by the removal of 


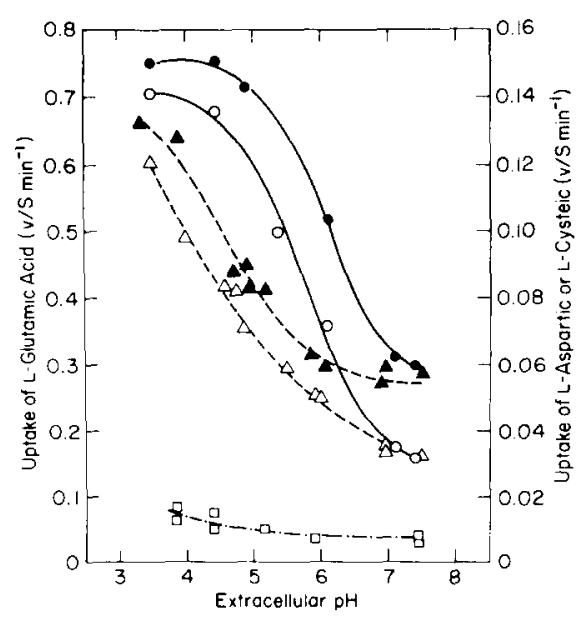

Fig. 1. pH profile of the uptake of the L-forms of glutamic, aspartic and cysteic acids. The uptake was studied for 3 min from $\mathrm{Na}^{+}$-containing (closed symbols) or $\mathrm{Na}^{+}$-free (open symbols) medium, at a substrate concentration of $2 \mathrm{mM}$. Circles, L-glutamic acid; triangles, L-aspartic acid; squares, L-cysteic acid.

$\mathrm{Na}^{+}$. The uptake of L-aspartic acid was qualitatively similar, although much slower. The uptake of L-cysteic acid, tested only in $\mathrm{Na}^{+}$-free medium, was even slower and only moderately stimulated by a $\mathrm{pH}$ drop from 7.4 to 4.0 (Fig. 1).

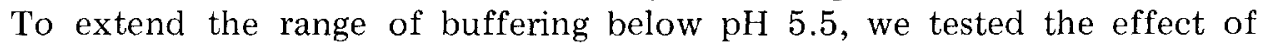
replacing phosphate with succinate, acetate, dimethylglutarate or $p$-aminobenzoate. These all inhibited the uptake of glutamic and 2-aminoisobutyric acids from acidic medium, and induced some cellular swelling (about $20 \%$ at the lower $\mathrm{pH}$ values) and decrease of $\mathrm{K}^{+}$levels. These undesirable effects were probably related to passage of the weak acid through the cell membrane in its undissociated form, carrying a proton into the intracellular phase, since the dipolar ions $\epsilon$-aminocaproate $\left(\mathrm{p} K_{1}^{\prime}=4.5\right)$ and morpholinoethanesulfonate $\left(\mathrm{p} K_{2}^{\prime}=6.15\right)$ did not interfere with amino acid transport nor modify the water content of the cells. These last two buffers were selected for use below pH 5.5.

At $\mathrm{pH} 7.4$ a series of neutral amino acids was able to inhibit the uptake of L-glutamic acid by $50-70 \%$, the $K_{\mathrm{i}}$ value for the inhibition by each amino acid being in good agreement with the $K_{\mathrm{m}}$ value for its own transport via System A (Table I). The portion of L-glutamic acid uptake sensitive to neutral amino acids had about the same magnitude as the $\mathrm{Na}^{+}$-dependent component, no inhibition being observed in $\mathrm{Na}^{+}$-free medium. 2-Aminonorbornane-2-carboxylic acid was able to inhibit only a very small portion of the uptake of L-glutamic acid at $\mathrm{pH} 7.4$, apparently acting on a transport system other than System $A$, since its inhibitory effect was additive to that of 2 -aminoisobutyric acid. The acidic amino acids tested up to $20 \mathrm{mM}$ concentrations, L-glutamic acid itself, Laspartic acid and L-cysteic acid, did not inhibit at all the uptake of L-glutamic acid at $\mathrm{pH} 7.4$.

The activation of the transport of L-glutamic acid by $\mathrm{Na}^{+}$at $\mathrm{pH} 7.4$ was found to present simple saturation kinetics (graph not included), the dissociation constant for $\mathrm{Na}^{+}$being approx. $100 \mathrm{mM}$. Either $\mathrm{Li}^{+}$or $\mathrm{K}^{+}$largely failed to substitute 
TABLE I

KINETIC PARAMETERS FOR THE INHIBITION OF THE UPTAKE OF L-GLUTAMIC ACID BY OTHER AMINO ACIDS

Experiments at $\mathrm{pH} 7.4$ were carried out in Krebs-Ringer bicarbonate medium, although the results were not significantly different in Krebs-Ringer phosphate. Every value is the mean of at least two experiments. Values for $K_{\mathrm{m}}$ for System A were taken from the refs. 12 and 17 . Experiments at pH 6.0 and 5.4 were carried out in modified Krebs-Ringer phosphate solution. Experiments at pH 4.5 were made with 20 or 40 $\mathrm{mM}$ c-aminocaproate as buffer. $\mathrm{Na}^{+}$was $100 \mathrm{mM}$ when present. $K_{\mathbf{i}}$ is the concentration of inhibitor that inhibited $50 \%$ of the sensitive uptake of L-glutamic acid, the sensitive portion being calculated by the method of Inui and Christensen [12]. $K_{\mathrm{m}}$, the half-saturation constant, was calculated from data obtained with the same cell population, using the inhibitor as substrate in this case.

\begin{tabular}{llcc}
\hline $\begin{array}{l}\text { Part 1, pH 7.4 } \\
\text { Inhibitor }\end{array}$ & $\begin{array}{l}\text { Inhibitable com- } \\
\text { ponent }(\%)\end{array}$ & $\begin{array}{l}K_{\mathrm{i}} \\
(\mathrm{mM})\end{array}$ & $\begin{array}{l}K_{\mathrm{m}} \text { for system A } \\
(\mathrm{mM})\end{array}$ \\
\hline 2-Aminoisobutyric acid & 67 & 1.4 & 1.5 \\
2-Aminonorbornane-2-carboxylic acid & 15 & & high \\
2-(Methylamino)-isobutyric acid & 55 & 0.5 & 0.3 \\
Glycine & 72 & 2.2 & 3.5 \\
L-Alanine & 56 & 0.8 & 0.7 \\
D-Alanine & 66 & 10 & 15 \\
L-Phenylalanine & 70 & 8 & 11 \\
- Part 2, lower pH values & Inhibitable com- & $K_{\mathrm{i}}$ & $K_{\mathrm{m}}$ \\
Inhibitor & ponent $(\%)$ & $(\mathrm{mM})$ & $(\mathrm{mM})$
\end{tabular}

\section{At $\mathrm{pH} 6.0$}

2-Aminoisobutyric acid

2-Aminonorbornane-2-carboxylic acid

Glycine

At pH 5.4

2-Aminoisobutyric acid

2-Aminonorbornane-2-carboxylic acid

\section{5}

40

9.5

0.2

12

4
0.3

7.5

3.6

0.2

8

At pH 4.5

2-Aminoisobutyric acid

2-Aminonorbornane-2-carboxylic acid

L-Methionine

L-Glutamic acid

43
54
60
70

16

0.2

0.35

70

At $\mathrm{pH} 4.5$, no $\mathrm{Na}^{+}$

2-Aminonorbornane-2-carboxylic acid

L-Methionine

59

60

70

0.18

0.3

0.15

L-Glutamic acid

* Value of $K_{\mathrm{i}}$ was difficult to estimate due to the small magnitude of the sensitive component.

** The uptake of methionine from $\mathrm{Na}^{+}$-containing medium was better resolved into two components with different affinity $\left(K_{\mathrm{m}}\right.$ values, 0.11 and $\left.10 \mathrm{mM}\right)$.

*** The values of $V$ for the saturable uptake of L-glutamic acid at pH 4.5 from $\mathrm{Na}^{+}$-containing and from $\mathrm{Na}^{+}$-free medium were 3.1 and $2.1 \mathrm{mmol} / \mathrm{kg}$ cell water per $\mathrm{min}$, respectively.

for $\mathrm{Na}^{+}$to allow transport, and $\mathrm{Ca}^{2+}$ or $\mathrm{Mg}^{2+}$ were also ineffective as substitutes (data not shown).

The portion of the uptake of glutamic acid sensitive to 2-aminoisobutyric acid gradually increased and changed from $\mathrm{Na}^{+}$dependent to $\mathrm{Na}^{+}$independent 
as the $\mathrm{pH}$ was lowered [1]. The uptake of 2 -aminoisobutyric acid itself at the same time became $\mathrm{Na}^{+}$independent and insensitive to inhibition by 2 -(methylamino)-isobutyric acid; furthermore it became fully sensitive to inhibition by the norbornane amino acid and able to stimulate exodus of the latter from previously loaded cells, the half-saturating constants indicating transport by a single shared system. Glycine was also effective at pH 4.6 (Table II). In contrast, 2-(methylamino)-isobutyric acid gained no transport interactions with the norbornane amino acid on lowering the $\mathrm{pH}$. These results, not presented here, show that 2-(methylamino)-isobutyric acid and the norbornane amino acid, but not 2-aminoisobutyric acid, retain their places as reliable model substrates for Systems A and L, respectively.

Table III summarizes the effects of some pertinent amino acids on the uptake of glutamic acid at three different $\mathrm{pH}$ values to show how its transport shifts from System A to System L by lowering the $\mathrm{pH}$. Leucine and alanine, not included in this table, were also effective inhibitors. The half-inhibiting concentrations of the norbornane amino acid were consistent with its half-saturation constant for its own transport at the same $\mathrm{pH}$ values (Table I). Similar results were obtained for the transport of aspartic acid, which was $60 \%$ inhibited by 2 (methylamino)isobutyric acid at $\mathrm{pH} 7.4\left(K_{\mathrm{i}}=0.3 \mathrm{mM}\right)$ although no effect could be observed at pH 4.5 for this amino acid, the uptake of aspartic acid becoming instead sensitive to the norbornane amino acid.

L- $\alpha$-Aminoadipic acid also presented an increasing uptake on acidification of the medium, which was $\mathrm{Na}^{+}$independent and sensitive to the norbornane amino acid. The same was true with D-glutamic acid, D- and L-aspartic acid and other dicarboxylic amino acids (Fig. 2).

The uptake of L-glutamic acid became easily saturable at $\mathrm{pH} 4.2$, the values estimated for its $K_{\mathrm{m}}$ being presented in Table I. A minor $\mathrm{Na}^{+}$-dependent portion of the saturable uptake of L-glutamic acid at $\mathrm{pH} 4.2$ was insensitive to 2-(methylamino)-isobutyric acid and to the norbornane amino acid, although it could be inhibited by L-methionine (Table III). Another series of experiments showed that the uptake of L-glutamic acid included no saturable component in the presence of excess methionine either in $\mathrm{Na}^{+}$or in choline media, or in the presence of excess norbornane amino acid in choline medium, although a saturable component was observed in the last case when $\mathrm{Na}^{+}$was also present in the incu-

TABLE II

COMPARATIVE STIMULATION OF THE 1-MIN EXODUS OF THE $\left[{ }^{14} \mathrm{C}\right]$ NORBORNANE AMINO ACID BY FIVE AMINO ACIDS, $10 \mathrm{mM}$ IN pH 4.6 MEDIA

Typical results at $37^{\prime \prime} \mathrm{C}$. In parallel experiments, 2-(Methylamino)-isobutyric acid was quite as ineffective as sarcosine and proline. The effect of glycine is significant.

\begin{tabular}{llc}
\hline External amino acid & $\begin{array}{l}\text { Residual cellular }{ }^{14} \mathrm{C} \\
(\mathrm{mol} / \mathrm{kg} \text { cell water) }\end{array}$ & Percent of control \\
\hline Noni & 2.96 & $(100)$ \\
Methionine & 0.63 & 21 \\
2-Aminoisobutyric acid & 1.61 & 54 \\
Glycine & 2.69 & 91 \\
Sareosine & 2.97 & 100 \\
Proline & 2.99 & 101 \\
\hline
\end{tabular}


TABLE III

EFFECTS OF SEVERAL AMINO ACIDS ON THE UPTAKF OF L-GLUTAMIC ACID AT VARIOUS pH VALUES

The incubation medium was modified Krebs-Ringer phosphate solution for the experiments at pH 6.0, and it contained 20 or $40 \mathrm{mM}$ e-aminocaproate as buffer in the other cases. Uptake was studied during a $3-\mathrm{min}$ period. $\mathrm{Na}^{+}$, when present, was $100 \mathrm{mM}$.

Inhibitor

None

$5 \mathrm{mM}$ 2-Aminonorbornane-

2-carboxylic

$50 \mathrm{mM}$ 2-(Methylamino)-

isobutyric

Both amino acids

$5 \mathrm{mM}$ L-Methionine

$20 \mathrm{mM} \mathrm{L}$-Glutamic
Uptake of L-glutamic ( $([/ S]$ per min)

\begin{tabular}{|c|c|c|c|c|c|}
\hline \multicolumn{2}{|c|}{ At pH 6} & \multicolumn{2}{|c|}{ At $\mathrm{pH} 4.5$} & \multicolumn{2}{|c|}{ At pH 3.8} \\
\hline $\begin{array}{l}\mathrm{Na}^{+} \\
\text {medi- } \\
\text { um }\end{array}$ & $\begin{array}{l}\mathrm{Na}^{+} \text {-free } \\
\text { medium }\end{array}$ & $\begin{array}{l}\mathrm{Na}^{+} \\
\text {medi- } \\
\text { um }\end{array}$ & $\begin{array}{l}\mathrm{Na}^{+} \text {-free } \\
\text { medium }\end{array}$ & $\begin{array}{l}\mathrm{Na}^{+} \\
\text {medi- } \\
\text { um }\end{array}$ & $\begin{array}{l}\mathrm{Na}^{+} \text {-free } \\
\text { medium }\end{array}$ \\
\hline 0.42 & 0.31 & 1.10 & 0.99 & 1.69 & 1.46 \\
\hline 0.34 & 0.25 & $0.52 *$ & $0.39 *$ & 0.65 & 0.44 \\
\hline 0.36 & 0.32 & $1.06 * *$ & $0.98 * *$ & 1.70 & 1.40 \\
\hline 0.29 & 0.24 & & & & \\
\hline 0.26 & 0.23 & $0.41 *$ & $0.38 *$ & & \\
\hline
\end{tabular}

* The increase of the concentration of the norbornane amino acid or methionine to $50 \mathrm{mM}$ did not increase significantly the inhibition obtained.

** With $50 \mathrm{mM}$ 2-aminoisobutyric acid the uptake was 0.77 in $\mathrm{Na}^{+}$and 0.49 in choline medium.

**** For $20 \mathrm{mM}$ D-glutamic acid, 0.88 .

bation medium. A double reciprocal plot of these latter values (not shown) permitted us to estimate the values for $V$ and $K_{\mathrm{m}}$ for this component as 1.3 $\mathrm{mmol} / \mathrm{kg}$ cell water per min and $12 \mathrm{mM}$, respectively. Table IV shows the sensitivity of this $\mathrm{Na}^{+}$-dependent component of the uptake of L-glutamic acid to various neutral amino acids. The relative reactivities are quite similar to those found at neutral $\mathrm{pH}$ for System ASC [18], although the strong inhibition pro-
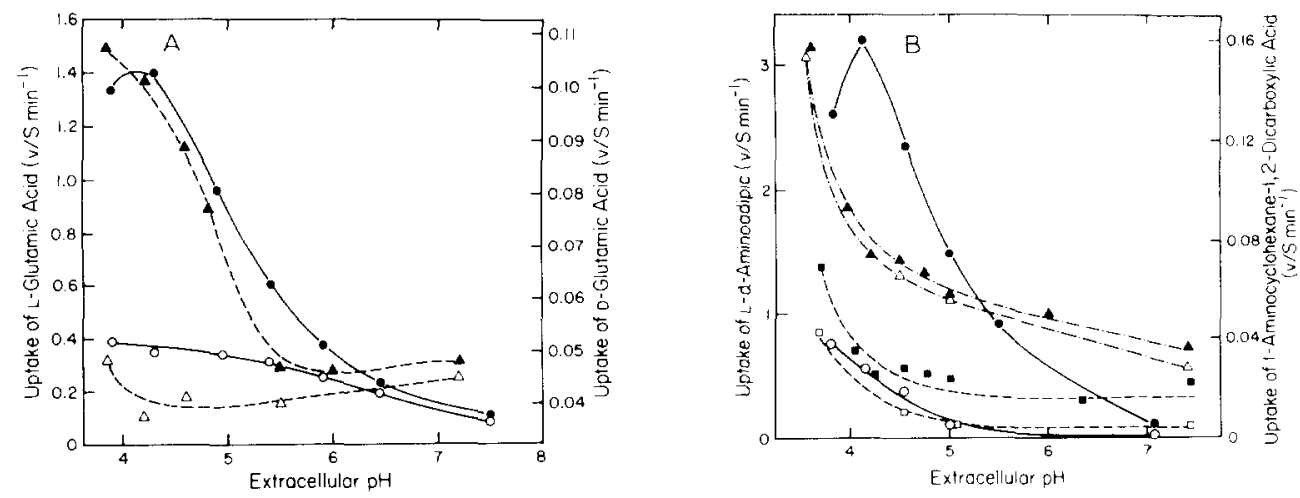

Fig. 2. pH profile of the uptake of various dicarboxylic amino acids from Na ${ }^{+}-\mathrm{fret}^{-}$medium. Closed symbols, amino acid alone. Open symbols, in the presence of excess norbornane amino acid. (A) $0.2 \mathrm{~m} M \mathrm{~L}$ (circles, scale at left) or D- (triangles, scale at right) glutamic acid. (B) $0.5 \mathrm{mM}$ L- $\alpha$-aminoadipic acid (circles, scale at left); $0.1 \mathrm{mM} 1$-aminocye!nhexane-1,2-dicarboxylic acid (scale at right), its more soluble isomer (triangles) or its less soluble one (squares). Uptake was studied in all the cases for 3 min. $\alpha-\Lambda m i n o-$ adipic acid was determined by the amino acid analyzer. 
TABLE IV

EFFECTS OF VARIOUS NEUTRAL AMINO ACIDS ON THE Na ${ }^{+}$-DEPENDENT COMPONENT OF THE UPTAKE OF L-GLUTAMIC ACID AT pH 4.3

Uptake was studied during $3 \mathrm{~min}$ from medium containing $90 \mathrm{mM} \mathrm{Na}^{+}, 20 \mathrm{mM} \epsilon$-aminocaproate as buffer, and $20 \mathrm{mM}$ norbornane amino acid. The concentration of the test amino acids was $30 \mathrm{mM}$. The inhibition produced by these amino acids was not observed in medium containing $20 \mathrm{mM}$ L-methionine instead of the norbornane amino acid. No significant inhibition, in addition to that produced by the norbornane amino acid, was observed in $\mathrm{Na}^{+}$-free medium.

Amino acid

L-Alanine

L-Serine

L-Threonine

L-Homoserine

L-Hydrox y proline

L-Valine

L-Phenylalanine

L-Methionine

2-Aminoisobutyric acid

Glycine

2-(Methylamino)-Isobutyric acid

(Removal of $\mathrm{Na}^{+}$)
Inhibition (\%)

42
47
43
67
$-10^{*}$
39
72
70
13
29
10
77

* The slight stimulation produced by hydroxyproline was also observed in $\mathrm{Na}^{+}$-free medium.

duced by L-phenylalanine and the absence of reactivity for hydroxy-L-proline are features not observed for that system at neutral $\mathrm{pH}$.

In contrast, the uptake of D-glutamic acid at $\mathrm{pH} 4.5$ was almost the same whether $\mathrm{Na}^{+}$was present or not in the incubation medium. In addition, the same inhibition of the transport, $84-85 \%$, was produced by a $30 \mathrm{mM}$ concentration of either the norbornane amino acid or of L-methionine, both in $\mathrm{Na}^{+}-$ containing and in $\mathrm{Na}^{+}$-free medium.

L-Glutamic acid and the other acidic amino acids except cysteic acid were able to inhibit the uptake of the norbornane amino acid and L-valine at acidic $\mathrm{pH}$ values. Fig. 3 illustrates the inhibition produced by a series of amino acids

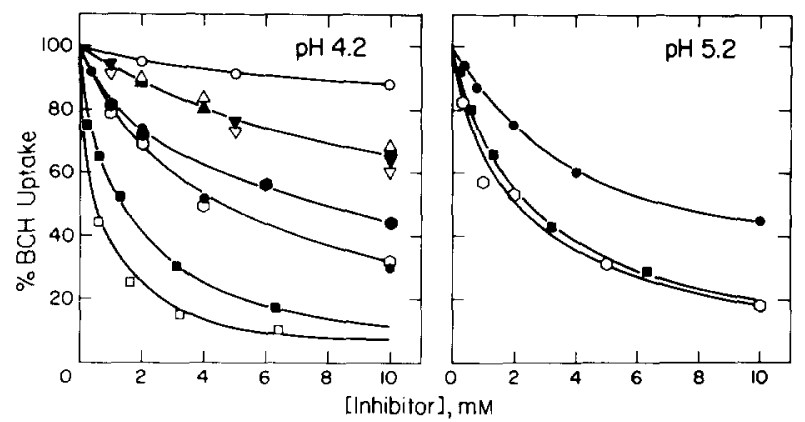

Fig. 3. Effects of various amino acids on the uptake of $0.02 \mathrm{mM}$ norbornane amino acid from $\mathrm{Na}^{+}$-free medium at $\mathrm{pH} 4.2$ (left) and 5.2 (right). Uptake was studied for $30 \mathrm{~s}$ from media containing $40 \mathrm{mM}$ $\epsilon$-aminocaproate as buffer, and expressed as percent of the uninhibited uptake: D-glutamic acid; -, L-glutamic acid; 0 , L-glutamine; $\alpha$-methyl-DL flutamic acid; $\therefore$, D-aspartic acid; 4 L-aspartic acid; $\because$ D-asparagine; $\nabla$, L-asparagine; $\square$, L- $\alpha$-aminoadipic acid; $\square, S$-carboxymethyl-L-cysteine. L-cysteic acid and D-glutamine, not represented in the figure, gave no significant inhibition. Similar experiments using L-valine as substrate instead of the norbornane amino acid gave similar results for the various inhibitors. 
at pH 5.2 and 4.2; for L-glutamic acid and L- $\alpha$-aminoadipic acid the inhibition increased on lowering the $\mathrm{pH}$, the reverse situation applying for L-glutamine. The values for $K_{\mathrm{i}}$ are presented in Table V.

The acidic amino acids stimulated the exodus from the cells of the previously loaded norbornane amino acid. At pH 4.2 the values for $K_{\mathrm{e}}$, the concentration of external amino acid producing a half-maximal effect, were consistent with the values for $K_{\mathrm{i}}$ of the amino acid acting on the uptake of the norbornane amino acid or L-valine (Table V). The value calculated for the maximal effect at $\mathrm{pH} 4.2$ was about the same for all the acidic amino acids tested, being consistently $2-3$ times greater than the maximal effect produced by the norbornane amino acid itself or by phenylalanine. Other neutral amino acids with lower affinity for System L, such as L-glutamine or L-valine, however, gave maximal effects similar to those found for acidic amino acids (Table V). At $20 \mathrm{mM} \mathrm{D}$ glutamic, D- and L-aspartic and L-cysteic acids stimulated exodus of the norbornane amino acid by only $67,99,138$ and $7 \%$ of the effect produced by 5 $\mathrm{mM}$ of the norbornane amino acid in correspondence with their smaller to negligible abilities to inhibit the uptake of the norbornane amino acid or L-valine (Fig. 3).

Methylation of the $\alpha$-amino group greatly decreased the affinity of acidic

TABLE V

KINETICS OF THE EFFECTS OF SEVERAL AMINO ACIDS ON THE UPTAKE AND ON THE EXODUS OF SYSTEM L SUBSTRATES AT PH 4.2

The uptake of $0.02 \mathrm{n} \mathrm{M}$ norbornane amino acid $(\mathrm{BCH})$ and $\mathrm{L}$-valine was studied during a 30 -s period in $\mathrm{Na}^{+}$-free medium containing $40 \mathrm{mM}$ e-aminocaproate as buffer. $K_{\mathrm{i}}$ was calculated as the concentration of test amino acid that inhibited $50 \%$ of the sensitive uptake. For the exodus experiments, cells were first loaded with the norbornane amino acid as described in Materials and Methods; the final intracellular concentration was about $2 \mathrm{~m}$. The exodus was then studied during $1 \mathrm{~min}$, and the values calculated as relative rates of exodus, $\left(S_{\mathrm{o}}-S_{\mathrm{t}}\right) / S_{\mathrm{t} / 2}$, where $S_{\mathrm{o}}$ and $S_{\mathrm{t}}=$ initial and final concentrations in the intracellular water, $S_{t / 2}=10^{1 / 2} \log \left(S_{\mathrm{o}} \cdot S_{t}\right)_{;}$finally, data were expressed as percent of the effect produced by 5 $\mathrm{mM}$ of the norbornane amino acid in the medium, and plotted according to Dixon for the calculation of maximal effect $(V)$ and the concentration that produces half-maximal effect $\left(K_{\mathrm{e}}\right)$. Units for these parameters are: for $V$, percent of the effect produced by $5 \mathrm{mM}$ the norbornane amino acid; and for $K_{\mathrm{e}}, \mathrm{m} M$. Figures in parentheses are data obtained loading the cells with the resolved $b(--)$-2-aminonorbornane-2carboxylic acid instead of the unresolved b( + )-form used in all other experiments. Medium was always $\mathrm{Na}^{+}$ free with $20 \mathrm{mM}$ e-aminocaproate as buffer.

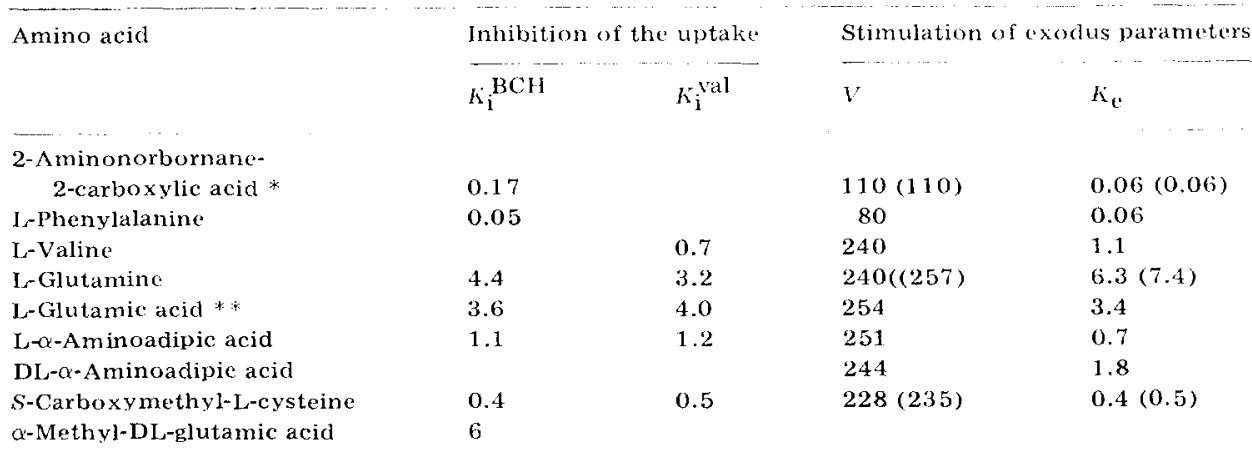

* For the b(t) preparation. The $K_{\mathrm{m}}$ iur the levorotatory isomer (b(-)) was $0.12 \mathrm{mM}$, and $K_{e}, 0.025$ $\mathrm{mM}$.

** At pH 5.2 the following values were estimated: $K_{1}^{\mathrm{BCH}}=7 \mathrm{mM} ; \nu^{\prime}=251 ; K_{\mathrm{e}}=12.5 \mathrm{mM}$. 
amino acids for System L, as shown by the observation that $20 \mathrm{mM} \mathrm{N}$-methylL-glutamic acid produced less than $10 \%$ inhibition of the uptake of the norbornane amino acid or valine. No effect was detected for $20 \mathrm{mM} \mathrm{N}$-carboxyglycine.

A methyl group on the $\alpha$-carbon of glutamic acid had almost no effect on its $K_{\mathrm{i}}$ for inhibiting uptake of the norbornane amino acid, judged by a comparison of the DL-form with the mean value for the two enantiomorphs of glutamic acid. In contrast, the $\alpha$-methyl derivative of DL-aspartic acid at $20 \mathrm{mM}$ concentration produced no inhibition of the uptake of the norbornane amino acid at $\mathrm{pH} 4.2$.

The D-forms of glutamic and $\alpha$-aminoadipic acids were much less effective substrates for transport than the L-isomers: Table $\mathrm{V}$ shows the $K_{\mathrm{e}}$ for DL- $\alpha$ aminoadipic acid was roughly double that for the L-form suggesting that the D-form has little or no activity, and Figs. 2 and 3 show that both the uptake of D-glutamic acid and its ability to inhibit the transport of the norbornane amino acid were only about one-tenth as great as for the L-isomer. The uptake of Dand L-forms of aspartic acid at $\mathrm{pH} 4.2$ and their ability to inhibit each others uptake were, however, about equal (data not presented), as were also their effects on the uptake (Fig. 3) and on the exodus of the norbornane amino acid.

Amidation of the terminal carboxyl group of glutamic or aspartic acid did not modify the reactivity for System $\mathrm{L}$ at $\mathrm{pH} 4.2$, although an increase of the reactivity of L-glutamine over L-glutamic acid was found at pH 5.2 (Fig. 3). The uptake of $\mathrm{D}$ - and L-asparagine from $\mathrm{Na}^{+}$-free medium at $\mathrm{pH} 4.2$ was identical in experiments in which the amino acid was determined with the amino acid analyzer, as were its effects on the uptake of the norbornane amino acid (Fig. 3). In contrast, the effects of glutamine on the uptake (Fig. 3) and on the exodus of the norbornane amino acid were very different for the L- and D-forms.

The uptake of the DL-forms of 1-aminocyclohexane-1,2-dicarboxylic acid, a cyclic aspartic acid analog, was found to be slow. This amino acid exists in two isomeric forms, depending on the orientation of the distal carboxyl group. A larger portion of the uptake of the less soluble isomer was sensitive to the norbornane amino acid than that of the more soluble one (Fig. 2). No inhibition of the uptake of the norbornane amino acid was produced by $10 \mathrm{mM}$ o-carboxyphenylalanine at $\mathrm{pH} 4.2$.

The presence of an imino group within the chain did not confer reactivity for System $L$ in the case of iminodiacetic acid, which failed to inhibit the uptake of the norbornane amino acid at $\mathrm{pH} 4.2$ at $20 \mathrm{mM}$ concentration. No interaction on uptake was found between $\mathrm{D}$ - or L-aspartic acid and $\beta$-alanine in $\mathrm{Na}^{+}$free medium at $\mathrm{pH} 4.2$, although aspartic acid did inhibit the uptake of $\beta$-alanine when $\mathrm{Na}^{+}$was present $(38-40 \%$ for $10 \mathrm{mM}$ aspartic acting on the uptake of $1 \mathrm{mM} \beta$-alanine).

The presence of a dissociable hydroxyl group, e.g. a phenolic group on a nitrobenzene ring, had an effect similar to that of an extra carboxyl group in restricting the $\mathrm{pH}$ range for uptake by System L, as shown for two hydroxynitro derivatives of phenylalanine and for $3^{\prime}, 5^{\prime}$-diiodotyrosine (Fig. 4). As these compounds were titrated to their forms without net charge, their uptake rate showed an increase that could be inhibited by excess norbornane amino acid and was $\mathrm{Na}^{+}$independent and insensitive to 2-(methylamino)-isobutyric acid. The kinetic analysis for $2^{\prime}$-hydroxy-5'-nitrophenylalanine showed that the 


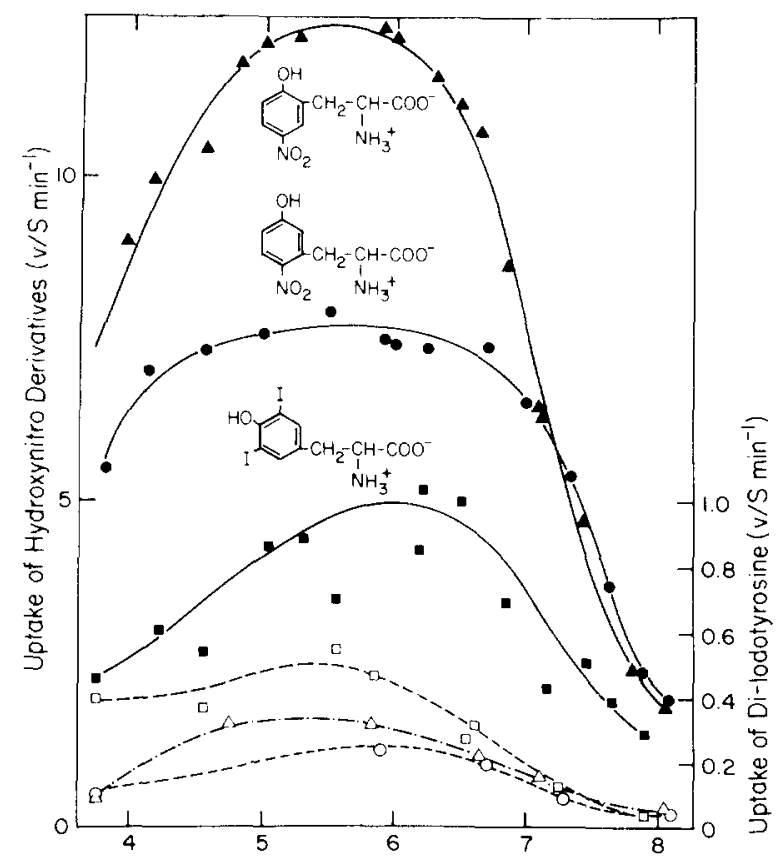

Fig. 4. $\mathrm{pH}$ profile of the uptake of nitro and iodo derivatives of hydroxyphenylalanine from $\mathrm{Na}^{+}$-free medium with (open symbols) and without (closed symbols) excess norbornane amino acid in the medium. Uptake was studied for $1 \mathrm{~min}$ from medium containing $20 \mathrm{mM}$ phosphate or $\epsilon$-aminocaproate as buffer. Circles, $0.2 \mathrm{mM} 55^{\prime}$-hydroxy-2'-nitrophenylalanine; triangles, $0.2 \mathrm{mM} 2^{\prime}$-hydroxy-5'-nitrophenylalanine: squares, $0.2 \mathrm{mM} 3^{\prime}, 5^{\prime}$-diodotyrosine. The uptake of the hydroxynitrophenylalanines was measured from their optical absorbances at $400 \mathrm{~nm}$; the uptake of diodotyrosine was determined from the uptake of the 125 l-labelled compound.

increase of the uptake from $\mathrm{pH} 7.2$ to 6.0 was due to a decrease in the apparent $K_{\mathrm{m}}$ without any change in $V$ (Fig. 5 ).

Below pH 4.5, a decrease of the uptake for the acidic amino acids by System L was usually observed (Figs. 2 and 4 ). This decrease was also seen for the reactive neutral amino acids tested (norbornane amino acid, phenylalanine and valine) and appears to be a property of the transport system. The intensity of the effect depended, however, on the particular substrate involved, as did the precise $\mathrm{pH}$ at which the decrease began to be observed.

Fig. 6 presents the $\mathrm{pH}$ profiles for the uptake of four acidic amino acids by System L, compared with the titration curves of their sidechain carboxyl or phenolic groups at $37^{\circ} \mathrm{C}$; the two last points on the more acidic side of the profile for L-glutamic acid and the last point for L- $\alpha$-aminoadipic acid have been corrected according to the decrease of the uptake of L-valine observed at those $\mathrm{pH}$ values. The half-maximal uptake was located in all the cases at a $\mathrm{pH}$ value near the $\mathrm{p} K_{2}^{\prime}$ value, although always displaced towards the alkaline side. The displacement seems to be the greatest in the case of the hydroxynitrophenylalanines, although that could be expected under the particular conditions used in these experiments, as will be discussed later.

Plots of $1 / v$ vs. $1 /\left[\mathrm{H}^{+}\right]$(not reproduced here) gave a linear relationship for the uptake rates of L- and D-glutamic acids and the two hydroxynitrophenyl- 

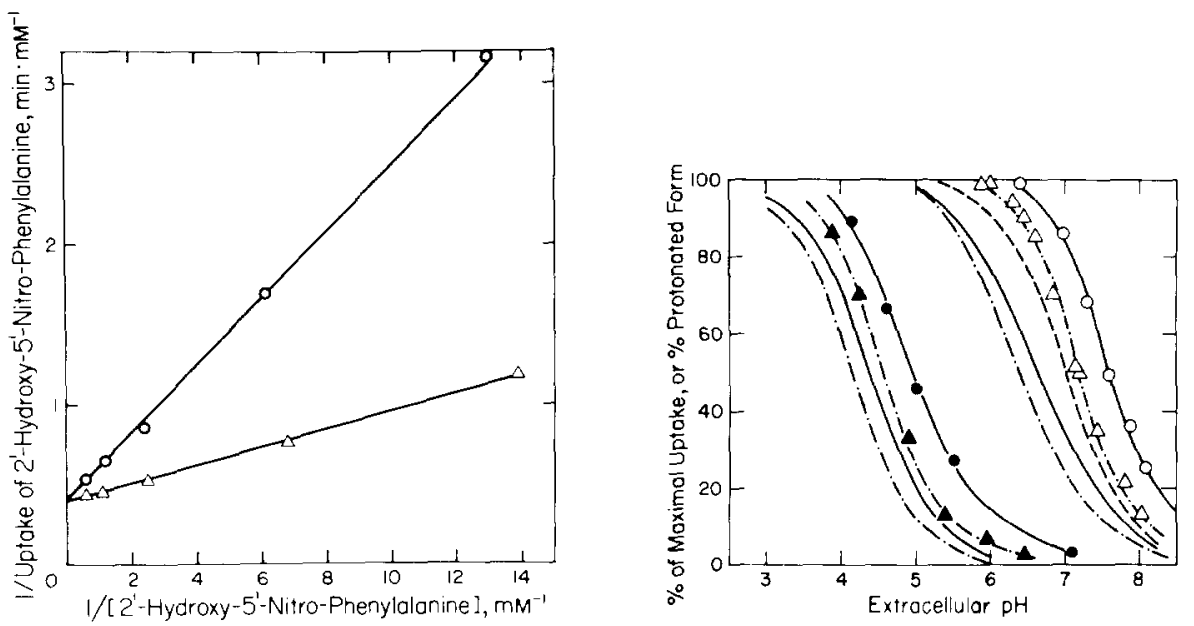

Fig. 5. Kineties of the uptake of $2^{\prime}$-hydroxy-5'-nitrophenylalanine from $\mathrm{Na}^{+}$-free medium at $\mathrm{pH} 6.0$ and 7.2. Uptake was measured from modified $\mathrm{Na}^{+}$-free Krebs-Ringer phosphate medium for 1 min. Ordinate, reciprocal of the uptake ( $\mathrm{mmol} / \mathrm{kg}$ cell water per $\mathrm{min}$ ). Abscissa, reciprocal of the mean concentration in the medium $(\mathrm{mM})$. Values estimated for the kinetic parameters were, at pH $7.2: V=2.4 \mathrm{mmol} / \mathrm{kg} \mathrm{cell}$ water per $\min ; K_{\mathrm{m}}=0.5 \mathrm{mM}$. At pH $6.0: V=2.5 \mathrm{mmol} / \mathrm{kg}$ cell water per $\mathrm{min} ; K_{\mathrm{m}}=0.14 \mathrm{mM}$. The values for $K_{\mathrm{m}}$ were similar to the values of $K_{\mathrm{i}}$ obtained when this compound twas used to inhibit the uptake of the norbornane amino acid.

Fig. 6. Comparison of the uptake of several acidic amino acids by System $L$ and the titration curves of the sidechain carboxyl or phenolic group at $37^{\prime \prime} \mathrm{C}$. The lines (from left to right) represent L-glutamic acid, L- $\alpha$-aminoadipic acid, 2'-hydroxy-5'-nitrophenylalanine and 5'-hydroxy-2'-nitrophonylalanine. Lines with symbols refer to uptake and those without them to titration curves. The dashed line represents values of " calculated from the equation:

$$
v=\frac{V \cdot[S]}{K_{m}\left\{1+\frac{K^{\prime}}{\left[\mathrm{H}^{+} \mid\right.}\right\}+[S]}
$$

by giving to the constants the values estimated for $2^{\prime}$-hydroxy-5'-nitrophenylalanine, i.e. $V=2.5 ; k_{\mathrm{m}}=$ $0.1 ; K^{\prime}=6.3 \cdot 10^{-8}$, and $[S]=0.2$.

\section{TABLE VI}

\section{EFFECTS OF THE TRANSPORT OF GLUTAMIC ACID AND THE NORBORNANE AMINO ACID ON THE INTRACELLULAR PH}

Incubation medium contained $40 \mathrm{mM}$ e-aminocaproate as buffer; no $\mathrm{Na}^{+}$was present. The initial pII of the medium was 4.35, and the final $\mathrm{pH} 4.44-4.46$. The initial intracellular $\mathrm{pH}$ is assumed to be about 7.4 . The intracellular $p H$ was calculated from the distribution of $\left.i^{14} \mathrm{C}\right]$ salicylic acid. Subsequent to these experiments we have discovered that cell homogenates bind salicylate to a moderate extent below $p H 5$, but not at the apparent cellular $\mathrm{pH}$ values encountered here.

\begin{tabular}{lll}
\hline & \multicolumn{2}{c}{ Intracellular pH * } \\
Additions & $3 \mathrm{~min}$ & $10 \mathrm{~min}$ \\
& & \\
None & 6.19 & 5.76 \\
$17 \mathrm{mM}$ L-glutamic acid & 6.00 & 5.65 \\
$17 \mathrm{mM}$ D-glutamic acid & 6.12 & 5.76 \\
$30 \mathrm{mM}$ the norbornane amino acid & 6.15 & 5.78 \\
The latter + $17 \mathrm{mM}$ L-glutamic acid & 6.13 & 5.75
\end{tabular}

* In 17 pairs of values with or without $10-20 \mathrm{mM} \mathrm{L}$-glutamic acid present, at an extracellular pH of 4.3-5.3 and with incubation time's of $1-15 \mathrm{~min}$, the apparent intracellular $\mathrm{pH}$ was always 0.102 \pm 0.016 (S.F.) unit lower in the cells incubated with glutamic acid. These results correspond to a value of $l^{2}<0.001$ (two-tailed paired $t$-test). All other differences were not significant in six similar experiments. 
alanines. From these plots the concentration of $\mathrm{H}^{+}$producing half-maximal stimulation of the transport, $K_{\mathrm{H}^{+}}$, can be calculated. The values for $\log \left(1 / K_{\mathrm{H}^{+}}\right)$were: 4.75 for L-glutamic acid, 4.60 for D-glutamic acid, 6.42 for 2 '-hydroxy-5' - nitrophenylalanine, and 7.02 for 5 '-hydroxy-2'-nitrophenylalanine, differing only by $0.2-0.6$ unit from the $\mathrm{p} K_{2}^{\prime}$ values at $37^{\circ} \mathrm{C}$ (Fig. 6).

Table VI shows that the fall in the intracellular $\mathrm{pH}$ upon incubation in acidic medium was significantly accelerated by the presence of L-glutamic acid in the medium, an observation suggesting that a cotransport of $\mathrm{H}^{+}$with the amino acid was taking place. This effect was eliminated by adding the norbornane amino acid in excess. In correspondence, the presence of D-glutamic acid, which is taken up much more slowly by System L, did not produce significant acceleration of changes in the intracellular $\mathrm{pH}$ under the same conditions.

\section{Discussion}

To interpret the $\mathrm{pH}$ effect on the uptake of glutamic acid, we had to bring ourselves to understand that two effects take place concurrently as the $\mathrm{pH}$ is lowered: The contribution of System A rapidly disappears, as it does for all neutral amino acids; and this contribution is replaced several times over by uptake by System L. The sum of these two components yields a pH profile with half-maximal stimulation lying between $\mathrm{pH} 5$ and 6 (Fig. 1), far from the $\mathrm{p} K_{2}^{\prime}$ of glutamic acid, the circumstance that led Heinz et al. [6] to propose a favorable protonation of the carrier rather than of the amino acid as the explantion of the increase in activity. For the transport of neutral amino acids by System $\mathrm{L}$ to be increased by lowering the $\mathrm{pH}$ to 5 is not unusual. That undoubtedly significant, structure-dependent effect has been discussed elsewhere [19] and is under our continuing study. But the basis for the large increase in the rate of glutamic acid uptake by System L proves much simpler: it arises mainly from the conversion of the unreactive glutamate anion into a neutral zwitterionic substrate by the protonation of the distal carboxyl group. The rate of glutamic acid uptake thereby attained at $\mathrm{pH} 4.5$ is of the same order as that seen for neutral amino acids at various $\mathrm{pH}$ values.

Our identification of the routes of glutamic acid uptake was at first confounded by the observation that 2 -aminoisobutyric acid changes from a $\mathrm{Na}^{+}$dependent to a $\mathrm{Na}^{+}$-independent inhibitor of glutamic acid uptake as the $\mathrm{pH}$ is lowered. A reappraisal of the systems specificities of 2 -aminoisobutyric and 2 (methylamino)-isobutyric acids and the norbornane amino acid showed that the latter two retain their specificities to Systems $A$ and $L$, respectively, as the $\mathrm{pH}$ is lowered to 4.2. Between these two amino acids we find no measurable cis or trans interactions for transport. This result continues a consistent series of observations in this laboratory that these two are in our cell line trustworthy model substrates for Systems A and L [20,21]. 2-Aminoisobutyric acid in contrast now loses any confidence it has had as a model substrate for System A. At pH 5 almost all of its mediated uptake is $\mathrm{Na}^{+}$independent and insensitive to 2 (methylamino)-isobutyric acid. The component with these properties doubles in rate as the $\mathrm{pH}$ is lowered from 7.4 . We will report elsewhere on such substrate structure-determined intensifications of System $\mathrm{L}$ transport.

Our results appear consistent with some observations of Geck and Pfeiffer 
[22]. These authors considered glutamic acid uptake to be the sum of two components, one saturable ("Mechanism I"), and the other non-saturable ("Mechanism II"). The first of these was increased by lowering the $\mathrm{pH}$ and became $\mathrm{Na}^{+}$independent. This $\mathrm{Na}^{+}$-independent operation of "Mechanism I" we would now attribute to System L. Their second mechanism was $\mathrm{Na}^{+}$dependent and subject to inhibition by glycine or glutamine at neutral $\mathrm{pH}$. Lowering the $\mathrm{pH}$ was said not to increase this component. At neutral $\mathrm{pH}$ values the component described should be due to System A, but we are under difficulty to account for the survival of this component at low $\mathrm{pH}$. That behavior could arise from the replacement of System A uptake by a non-mediated component of uptake as the $\mathrm{pH}$ is lowered, such as we observed with commercial samples of $\left[{ }^{14} \mathrm{C}\right]$ glutamic acid. The appearance of sensitivity of "Mechanism I" to glycine when the $\mathrm{pH}$ is lowered corresponds to our present finding that glycine, as well as 2-aminoisobutyric acid, becomes a substrate of System L at low pH (Table II). Glutamine is reactive with System $\mathrm{L}$ throughout the $\mathrm{pH}$ range under study.

The reactivity of acidic amino acids with System L increases as the chain length is increased from 4 to 5 to 6 carbon atoms, in a way that might well be accounted for by the favorable effect of apolar mass, which has almost universally proved favorable to amino acid transport, other factors being equal [23]. Our tests with the three tyrosine analogs show that the site does not apply narrow limits as to the nature or the position of the acidic group necessary for System $\mathrm{L}$ transport of anionic amino acids; all that seems to be required is protonation to mask the negative charge.

The uptake of acidic amino acids follows kinetics of cotransport with $\mathrm{H}^{+}$ that can be described by the equation:

$$
v=\frac{V \cdot[S]}{K_{\mathrm{m}}\left\{1+\frac{K_{\mathrm{H}^{+}}}{\left[\mathrm{H}^{+}\right]}\right\}+[S]}
$$

The linearity of the plots of $1 / v$ vs. $1 /\left[\mathrm{H}^{+}\right]$and the finding that the changes in $\mathrm{pH}$ modify the apparent affinity more than the capacity of the system (Fig. 5 for 2 '-hydroxy-5'-nitrophenylalanine) support the model described by the above equation. This model demands that either the carrier or the substrate must be protonated before the carrier-substrate complex can be formed, but no different kinetic relations are to be expected depending on which of them, the carrier or the substrate, is actually protonated. A value for $K_{\mathrm{H}^{+}}$independent of substrate structure would, however, be expected if it is the carrier that protonates. In the present case, the values of $K_{\mathrm{H}^{+}}$do change with amino acid structure; hence the protonation must concern either the amino acid itself or the amino acid-site combination, but not the site itself.

The upward displacement of the midpoints of the transport curves in Fig. 6 with respect to the titration curves of the second acidic (carboxylic or phenolic) group in free solution could measure the degree of stabilization of these groups in their protonated forms through combination with the site, which is another way of speaking of the protonation of the substrate-site complex. The free energy of the binding step, if it refers only to one partner in a $\mathrm{H}^{+}$dissociation, will inevitably shift the apparent position on the $\mathrm{pH}$ scale of the titration of the 
site with the substrate, to a degree depending on substrate concentration. We can approximate the correction for this effect by assuming that the $K_{\mathrm{m}}$ for transport measures binding of the protonated species. In Fig. 6 we have drawn a dotted line taking this effect into account, by introducing the kinetic parameters calculated in Fig. 5 into the equation of the preceding paragraph, and also substituting $K_{\mathrm{H}^{+}}$for $K_{2}^{\prime}$. Now the difference between the theoretical and the experimental values for the $\mathrm{pH}$ at which half-maximal stimulation takes place is only $0.2 \mathrm{pH}$ unit. Another factor may be the stabilization of the protonated species arising because the carboxyl group is thrust into a somewhat apolar environment when the amino acid binds at the site, but that effect on the midpoint $\mathrm{pH}$ is presumably included in the correction already applied. Accordingly we conclude that the acidic amino acids are taken up as neutral zwitterions by System L under $\mathrm{pH}$ profiles only slightly displaced from their titration curves in free solution.

This model predicts uptake of $\mathrm{H}^{+}$into the cytoplasm if its $\mathrm{pH}$ is well above $\mathrm{p} K_{2}^{\prime}$. We observe qualitative support for that prediction (Table VI).

Table VII serves here to show the sharp fall-off in the transport rate in going from glutamic acid to aspartic acid differs from that between $\alpha$-aminoadipic acid and glutamic acid in that it is restricted to the L-isomer. From the behavior of the three tyrosine derivatives, we conclude that the acidic group need not fall at a precisely specified point in space. Therefore we take the change in stereospecificity seen with aspartic acid to mean that its carboxyl group takes an especially unfavorable position in the L-isomer, perhaps one so close to the functional groups on the $\alpha$-carbon as to cause difficulty for transport. This difficulty is we presume avoided for the D-isomer. That interpretation is supported by the effects of $\alpha$-methylation, which has no perceptible effect on the reactivity shown by glutamic acid but eliminates that of aspartic acid (Table VII). This difference suggests a special sensitivity of aspartic acid to a small change in the position taken by its sidechain, relative to the functional groups on the $\alpha$-carbon atom.

We were led then to wonder what feature of the $\beta$-carboxylic group causes difficulty for transport of L-aspartic acid. We came to the answer that the troublesome feature of the carboxyl group is the carbonyl group and not the hydroxyl group, because both glutamic acid and glutamine show the same

TABLE VII

Comparison of stereospecificity of the reaction of three dicarboxylic amino acids and the $\omega$-amides of two of them with System L. The values tabulated here are calculated from the reciprocals of the $K_{\mathfrak{i}}$ (or $K_{\mathrm{e}}$ ) values in Fig. 3 and Table IV, setting the value for L-glutamie acid at 100 . The parenthetic value is calculated from the values for the $L$ and DL forms.

\begin{tabular}{lccc}
\hline TABLE VII & L & DL & D \\
\hline Q-Aminoadipic acid & 407 & 190 & $(-27)$ \\
Glutamic acid & 100 & & 9 \\
Aspartic acid & 23 & & 21 \\
Glutamine & 90 & & 5 \\
Asparagine & 27 & & 29 \\
$\alpha$-Methylglutamic acid & & 58 & \\
$\alpha$-Methylaspartic acid & & 0 &
\end{tabular}


moderate stereospecificity, whereas both aspartic acid and asparagine show the same lack of stereospecificity (Table VII).

Pall [24] has reported a fall-off in transport in Neurospora in passing from glutamate to aspartate similar to that found here, except that the amino acids were in that case transported as anions. Transport systems with the anionic forms as substrates are also known for Escherichia coli [25], hepatic mitochondria [26], brain slices [27] and the hepatocyte (Kleinzeller, A., personal communication). Cysteic and homocysteic acids have served as model substrates for such systems. In agreement with our other results, cysteic acid showed no measurable uptake by the Ehrlich cell, either at pH 7.4 or 4.0 (Fig. 1), and even at $20 \mathrm{mM}$ this anion had no effect on the uptake of glumatic acid at $\mathrm{pH} 6$, nor on the uptake or the exodus of the norbornane amino acid at $\mathrm{pH} 4.2$.

Whether System A also accepts glutamic acid only as the $\alpha, \alpha$-zwitterion, thereby accounting for our inability to saturate this system by raising the glutamic acid concentration, we cannot tell because we do not yet know how to protonate its sidechain without at the same time terminating the activity of System $\mathrm{A}$. For the case of the small $\mathrm{Na}^{+}$-dependent component observed at low $\mathrm{pH}$ and showing the attributes of System ASC [13], including high stereospecificity, the acceleration on lowering the $\mathrm{pH}$ indicates that glutamic acid needs also to be protonated. By analogy with the known transport of glutamine by System ASC [13], glutamic acid in its principal isoionic form would be expected to be a substrate of that system.

Although we attribute the favorable effect of decreasing the $\mathrm{pH}$ on glutamic acid uptake by System L to the protonation of the amino acid, an effect of another kind sets in when the $\mathrm{pH}$ is brought below 4, namely a general inhibition of transport by System L. This effect also occurs for neutral amino acids below $\mathrm{pH}$ 5. A protonation of the transport system itself could be responsible for this effect. The $\mathrm{pH}$ range in which this change takes place depends on the structure of even the neutral substrates, an observation suggesting that the interfering protonation applies to the amino acid-carrier complex.

These results showed us, despite the considerable study that amino acid transport has had, a new world of relations on increasing the external $\mathrm{H}^{+}$concentration by two or three orders or magnitude.

\section{Acknowledgments}

Support from the Institute of Child Health and Human Development (Grant HDO1233) of the National Institutes of Health, U.S.P.H.S., is gratefully acknowledged. Dr. Garcia-Sancho was supported by the Fundacion Juan March, Madrid, Spain and Dr. Sanchez by the Ministerio de Educacion y Ciencia, Madrid, Spain. Amino acid analyzer determinations were made by M.E. Handlogten.

\section{References}

1 Christensen, H.N., Handlogten, M.E., Garcia-Sancho, J. and Sanchez, A. (1976) in Amino Acid Transport and Unic Acid Transport (Silbernagl, S., Lang, F. and Greger, R., eds.), pp. 5-12, Georg Thieme. Stuttgart

2 Christensen, H.N., Garcia-Sancho, J., Handlogten, M.E. and Sanchez, A. (1976) Fed. Proc. 36,1758

3 Christensen, H.N., Garcia-Sancho, J., Handlogten, M.E. and Sanchez, A. (1976) Abstr. 303, Tenth International Congress of Biochemistry, Hamburg 
4 Christensen, H.N. and Liang, M. (1965) J. Biol. Chem., 240, 3601-3608

5 Heinz, E., Loewe, U., Despopoulos, A and Pfeiffer, B. (1964) Biochem. Z. 340, 487-502

6 Heinz, E., Pichler, A.G. and Pfeiffer, B. (1965) Biochem. Z., 342, $542-552$

7 Christensen, H.N. (1969) Adv. Enzymol. 32, 1-20

8 Burckhalter, J.H. and Stephens, V.C. (1951) J. Am. Chem. Soc. $73,56-58$

9 Christensen, H.N. and Cullen, A.M. (1973) Biochim. Biophys. Acta 298, 932-950

10 Tager, H.S. and Christensen, H.N. (1972) J. Am. Chem. Soc. 94, 968-972

11 Clarke, H.T. (1955) in Organic Synthesis Coll. (Horning, E.C., ed.), Vol. III, pp, 226-227

12 Inui, Y. and Christensen, H.N. (1966) J. Gen. Physiol. 50, 203-224

13 Christensen, H.N., Liang, M. and Archer, E.G. (1967) J. Biol. Chem. 242, 5237-5246

14 Pal, P.R. and Christensen, H.N. (1961) J. Biol. Chem. 236, 894-897

15 Messineo, L. and Musarra, E. (1972) Int. J. Biochem. 3, 691-699

16 Christensen, H.N. (1975) Biological Transport, 2nd edn., pp. 446-447, W.A. Benjamin, Reading, Mass.

17 Christensen, H.N., Oxender, D.L., Liang, M. and Vatz, K. A. (1965) J. Biol. Chem. 240, 3609-3616

18 Thomas, E.L. and Christensen, H.N. (1971) J. Biol. Chem. 246, 1682-1688

19 Christensen, H.N., de Cespedes, C., Handlogten, M.E. and Ronquist, G. (1974) Ann. N.Y. Acad. Sci. $227,355-379$

20 Christensen, H.N. (1975) in Current Topics in Membranes and Transport (Bronner, F. and Klein. zeller, A., eds.), Vol. 6, pp. 227-257, Academic Press, New York

21 Christensen, H.N., de Cespedes, C., Handlogten, M.E. and Ronquist, G. (1973) Biochim. Biophys. Acta $300,487-522$

22 Geck, P. and Pfeiffer, B. (1972) in Na-linked Transport of Organic Solutes (Heinz, E., ed.), pp. 91-98. Springer Verlag, Berlin

23 Oxender, D.L. and Christensen, H.N. (1963) J. Biol. Chem. 238, 3686-3699

24 Pall, M.L. (1970) Biochim. Biophys. Acta 211, 513-520

25 Halpern, Y.S. and Lupo,M. (1965) J. Bacteriol. 90, 1288-1295

26 Meyer, J. and Vignais, P.M. (1973) Biochim. Biophys. Acta 325, 375-384

27 Blasberg, R.G. (1968) in Progress in Brain Research (Lajtha, A. and Ford, D.H., eds.), Vol. 29, pp. 245-256, Elsevier, Amsterdam 